\title{
Experimental characterization and automatic identification of stridulatory sounds inside wood
}

\author{
Carol L. Bedoya ${ }^{1, *}$, a), Ximena J. Nelson ${ }^{1}$, Eckehard G. Brockerhoff ${ }^{2, b)}$, Stephen Pawson ${ }^{2, c)}$, \\ and Michael Hayes ${ }^{3}$ \\ ${ }^{1}$ School of Biological Sciences, University of Canterbury, Private Bag 4800, Christchurch, New Zealand. \\ ${ }^{2}$ SCION (New Zealand Forest Research Institute), PO Box 29237, Christchurch, New Zealand. ${ }^{3}$ Department of \\ Electrical and Computer Engineering, University of Canterbury, Private Bag 4800, Christchurch, New \\ Zealand.*electronic mail: CLBedoya.contact@gmail.com
}

\begin{abstract}
The propagation of animal vocalizations in water and in air is a well-studied phenomenon, but sound produced by bark and wood boring insects, which feed and reproduce inside trees, is poorly understood. Often being confined to the dark and chemically-saturated habitat of wood, many bark- and woodborers have developed stridulatory mechanisms to communicate acoustically. Despite their ecological and economic importance and the unusual medium used for acoustic communication, very little is known about sound production in these insects, or their acoustic interactions inside trees. Here, we use bark beetles (Scolytinae) as a model system to study the effects of wooden tissue on the propagation of insect stridulations and propose algorithms for their automatic identification. We characterize distance-dependence of the spectral parameters of stridulatory sounds, propose data-based models for the power decay of the stridulations in both outer and inner bark, provide optimal spectral ranges for stridulation detectability, and develop automatic methods for their detection and identification. We also discuss the acoustic discernibility of species cohabitating the same $\log$. The species tested can be acoustically identified with $99 \%$ of accuracy at distances up to $20 \mathrm{~cm}$ and detected to the greatest extent in the $2-6 \mathrm{kHz}$ frequency band. Phloem was a better medium for sound transmission than bark.
\end{abstract}

Keywords: Acoustic communication, Bark beetles, Forest insects, Scolytinae, Sound production, Machine Learning

\footnotetext{
a) Current address: Verum Group, 97 Nazareth Avenue, Christchurch, New Zealand

b) Current address: Swiss Federal Research Institute WSL, Zürcherstrasse 111

8903, Birmensdorf, Switzerland. Also at School of Biological Sciences, University of Canterbury, Private Bag 4800, Christchurch, New Zealand

c) Current address: School of Forestry, University of Canterbury, Private Bag 4800, Christchurch, New Zealand
} 


\section{INTRODUCTION}

Forest soundscapes are a recurrent topic in acoustic, ecological, and sociological studies (Dumyahn and Pijanowski, 2011; Ross and Mason, 2017; Burivalova et al., 2019). These sounds can inform our understanding of the interactions between animals and their habitat (Dumyahn and Pijanowski, 2011; Pijanowski et al., 2011). Nonetheless, attention is biased toward sounds that propagate through air or water - neglecting local soundscapes occurring in other propagation media. One of these is wood, within which some insects (e.g., bark beetles (Scolytinae), wood borers (e.g., Cerambycidae, Bostrichidae and Ptinidae), pinhole borers (Platypodinae), and termites (Isoptera)) communicate acoustically (Birch and Keenlyside, 1991; Lai et al., 2017; Bedoya et al., 2019c). We know very little about communicatory interactions inside wood/bark and the transmission of acoustic information within these media (Hill et al., 2019). In order to address this, we use bark beetles (Coleoptera: Curculionidae: Scolytinae) to study the propagation and attenuation of stridulatory sounds inside trees. We also propose strategies for the automatic acoustic detection and identification of bark beetles and woodborers so that they can be acoustically studied without disrupting their natural habitat.

Bark beetles are a subfamily of weevils that spend most of their life cycle inside plant tissue (Kirkendall et al., 2015; Raffa et al., 2015) and are one of the very few animals that have evolved sound production mechanisms to communicate inside plants (Bedoya et al. 2019c; Hofstetter et al., 2019). Although 'bark beetle' is usually used to refer to all the Scolytinae, 'true bark beetles' are the subset that live, feed, and reproduce in the phloem tissue of trees (i.e., phloeophagy) (Kirkendall, 1983; Wood and Bright, 1982). There are ca. 6000 described species of Scolytinae (Kirkendall et al., 2015) distributed in all regions of the world except Antarctica (Raffa et al., 2015). Previous studies of bark beetle life history and behavior typically focus on the $<1 \%$ of species that are important forest pests that attack and potentially kill trees (Grégoire et al., 2015; Kirkendall et al., 2015).

Bark beetles typically construct an intricate system of tunnels (also referred to as galleries) within trees, where adults and larvae feed and complete their development (Hofstetter et al., 2019). Some bark beetles use airborne pheromones to communicate over large distances that facilitate aggregation or disrupt aggregations of conspecifics (Raffa et $a l ., 2015)$, and acoustic signals, on and within the host, for intraspecific communication over 
short distances (Rudinsky and Michael, 1973; Ryker and Rudinsky, 1976). However, the sounds of only a few, typically economically important, species have been reported in the literature. From the limited data available, acoustic signaling appears to be widespread within the group, but remains poorly documented (Barr, 1969; Lyal and King, 1996; Bedoya et al., 2019c). Sound production in Scolytinae is mediated by three predominant types of stridulatory organs: elytro-tergal, vertex-pronotal, and gula-prosternal (Barr, 1969; Lyal and King, 1996; Bedoya et al., 2019c). These organs can arise in one, both, or neither of the sexes, and, in studies to date where both sexes stridulate, the organ and the signals are usually sexually dimorphic (Lyal and King, 1996; Bedoya et al., 2019c; Hofstetter et al., 2019). Each stridulatory organ consists of two parts; A) a static file of teeth, also known as pars stridens, and B) a movable plectrum consisting of a set of spines, tubercles, or teeth that rubs against the static file (Barr, 1969). Acoustic characteristics of the stridulatory sounds vary between species (Fleming et al., 2013; Yturralde and Hofstetter, 2015; Bedoya et al., 2019a). Such characteristics are also dependent on the behavioral context (Fleming et al., 2013; Bedoya et $a l ., 2019$ a), as acoustic communication is used in several functions, including distress, premating recognition, rivalry, and copulation (Barr, 1969; Lyal and King, 1996; Fleming et al., 2013).

Given how little we know about bark beetle and woodborer stridulatory behavior in in general, it is unsurprising that the effect of the propagation medium on their sounds has not been assessed. Previous studies have mostly focused on the analysis of mechanical sounds (e.g., chewing), or the vibrational movement of insect larvae and pupae (Mankin et al., 2011; Jalinas et al., 2019; Sutin et al., 2019). However, the specific effect of wood and bark tissue on the propagation of acoustic communication (i.e., signals produced by acoustic organs) has yet to be investigated. Several theoretical methods have been developed for studying sound attenuation and absorption by trees (Burns, 1979; Price et al., 1988) and wood (Wassilieff, 1996; Legg and Bradley, 2016); however, these models are typically used to estimate wood characteristics and have yet to be experimentally verified using biotic sound sources.

The goal of our study was to address several unresolved issues related to the propagation of stridulatory sounds inside wood, so that this new information can be used for the acoustic detection and identification of insects inside trees. We analyzed the acoustic 
signals of two bark beetles, Hylastes ater Paykull and Hylurgus ligniperda (Fabricius), in order to characterize distance-dependent changes in the spectro-temporal features of stridulations propagating through wood. We determine which part of the audible spectrum is the most suitable to acoustically detect stridulations and investigate the maximum distances at which the presence of a bark beetle can be acoustically detected and the species identified. Then, we propose a data-based model for the attenuation of stridulatory sounds through wood, taking into consideration the type of tissue and its width. Finally, we implement a method for the acoustic detection and identification of stridulations, and provide suggestions for future improvements.

\section{METHODS}

\subsection{Subjects}

Hylastes ater and Hylurgus ligniperda were selected to study the propagation of stridulatory sounds inside wood because physical interactions (e.g., touching) trigger stridulatory behavior in males (Bedoya et al., 2019c), and thus, sound production can be manually elicited by the researcher. Hylurgus ligniperda has one of the highest known calling rates of all bark beetles (Bedoya et al., 2019a, 2019c) and tends to sing uninterruptedly for long periods (i.e., tens of minutes). Hylastes ater also responds acoustically to physical stimulation, although the duration of the stridulatory behavior is shorter than in H. ligniperda. Both species are less than $6 \mathrm{~mm}$ in body length (H. ater $4.0 \mathrm{~mm}$ and H. ligniperda $5.0 \mathrm{~mm}$, on average; Fig. 1) and colonize a variety of conifers, but mainly Pinus spp., including economically important species (Brockerhoff et al., 2003). Insects were manually collected from recently felled Pinus radiata D.Don logs in Bottle Lake Forest, Christchurch, New Zealand (-43²7'8.64" S $\left.172^{\circ} 41^{\prime} 42.00^{\prime \prime} \mathrm{E}\right)$. 


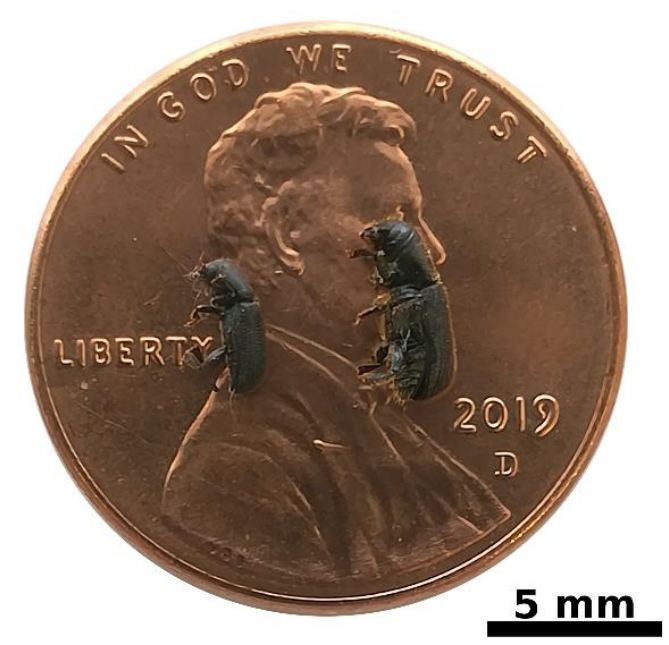

FIG. 1. Size comparison of males of Hylastes ater (left) and Hylurgus ligniperda (right) on an American penny.

\subsection{Experimental setup}

Recordings were acquired using a 352A24 monoaxial accelerometer (PCB piezotronics, Depew, USA) and a 744T recorder (Sound Devices, Reedsburg, USA). Analyzed signals were of one minute duration at a sampling frequency of $44100 \mathrm{kHz}, 48 \mathrm{~dB}$ gain, and 24-bit resolution. Two $P$. radiata $\operatorname{logs}(200 \mathrm{~cm}$ long, with respective mean \pm SD diameters of 19.2 \pm 0.3 and $26.4 \pm 0.7 \mathrm{~cm}$ ) were used during the experiment. The logs were held inside a temperature-controlled room at a constant temperature of $23^{\circ} \mathrm{C}$ for the duration of the experiments (14 days). Humidity inside the phloem was measured using a SHT85 sensor (Sensirion, Stäfa, Switzerland) after collecting data from each individual in each log in order to ensure humidity did not decline substantially.

\subsection{Data collection}

To estimate the effect of the outermost bark layer on signal acquisition, the experimental procedure was performed on the bark surface and inside the phloem tissue of two $P$. radiata logs of different diameters. Most bark- and woodborers live underneath the outermost bark tissue; thus, whether to pierce the bark is an important question that naturally arises before performing acoustic data acquisition in trees. Therefore, we tested tissue effects on each log, which had different average thicknesses of bark $(3.3 \pm 1.2 \mathrm{~mm} ; 8.5 \pm 1.3 \mathrm{~mm})$ and phloem $(2.6 \pm 0.5 \mathrm{~mm} ; 3.1 \pm 0.8 \mathrm{~mm})$. Subsequently, we recorded acoustic signals of $H$. ligniperda and $H$. ater at nine pre-allocated distances $(5,10,15,20,30,40,60,80$, and $100 \mathrm{~cm})$ from the 
position of the stridulating beetle (Fig. 2). Five beetles of each species were individually recorded in both logs with sensors located on the bark and in the phloem tissue at the respective nine distances ( $\mathrm{N}=5$ per species, 9 distances, 3 factors (beetle species, tissue type, $\log$ thickness), 2 levels per factor, $n=45$ per treatment, 360 recordings in total).

Beetles were individually inserted into a pre-drilled hole $(0.5 \mathrm{~cm}$ diameter $)$ through the outer bark into the phloem, at a distance of $20 \mathrm{~cm}$ from the edge of the log (Fig. 2). Then, the elytra of each beetle was softly touched with a paintbrush (Bockingford, 5700R, size 1) to trigger sound production as per Bedoya et al., (2019a,c). To record stridulations, the vibrational sensor (accelerometer) was attached to the bark, along the grain, using BluTack $^{\mathrm{TM}}$ at any of the nine discrete distances from 5 to $100 \mathrm{~cm}$ (Fig. 2). Once the signal was acquired, the sensor was randomly moved to a different position and data collection started again until data were acquired from all nine pre-allocated distances for each beetle. After signals were recorded on the bark of each of the two logs, $1 \mathrm{~cm}^{2}$ holes were carved into the bark until the phloem tissue was accessible. Then, the sensor was placed on the phloem and the experimental procedure was repeated, as previously described on the bark, using the same individuals.
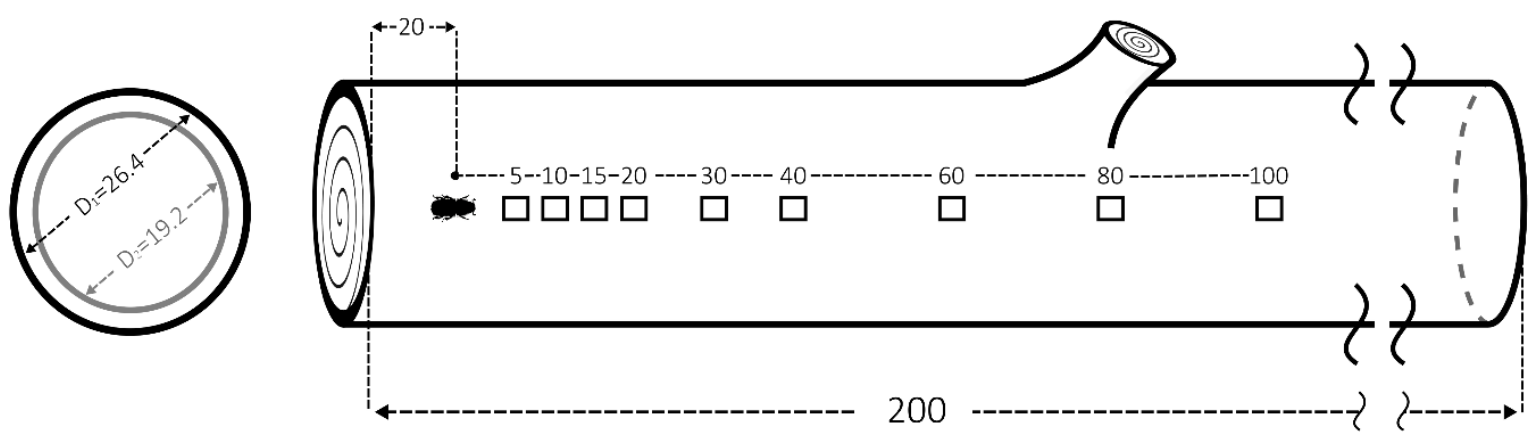

FIG. 2. Experimental setup for the analysis of sound propagation of two bark beetle species (Hylurgus ligniperda and Hylastes ater) in wood. $\mathrm{D}_{1}$ and $\mathrm{D}_{2}$ are the average diameters of the Pinus radiata logs used for testing. The beetle was placed $20 \mathrm{~cm}$ from one end of the $\log$. Stridulatory sounds produced by the individual were recorded at nonlinearly-spaced distances from 5 to $100 \mathrm{~cm}$. This procedure was repeated in the bark and phloem layer of each log. Dimensions in cm (not to scale). 


\subsection{Data analysis}

\subsubsection{Spectrogram and power spectrum estimation}

Spectrograms used for visualization were generated using a FFT of 1024 bins and a symmetric flat top window of 1024 samples with 3/4 overlap. Plots of power spectral density (PSD) were generated by averaging the PSDs of all test subjects for each species at each of the analyzed distances. The frequency-dependent power decay was estimated by averaging the mean PSD values from the signals of each species at every pre-determined distance (5$100 \mathrm{~cm}$ ) in frequency bands of $2 \mathrm{kHz}$. Power spectral densities were estimated using Welch's method. Power values hereafter are shown in $\mathrm{dB}$ Full Scale (dBFS), using the maximum power value of all signals as reference for the scaling.

\subsubsection{Experimental models}

Attenuation models were generated by fitting the average power decay from individuals of $H$. ligniperda and $H$. ater to exponential functions $\left(P(z)=\frac{\psi e^{-\alpha z}}{\varphi z}-c\right)$, where $\alpha$ is the frequency-dependent attenuation coefficient, $z$ is the distance between the sensor and the source, and $\varphi, \psi$, and $c$ are model constants in $\mathrm{dB}$. The exponential fitting was performed using nonlinear least squares on the averaged power levels at each distance. Recordings were separated by species, type of tissue, and tissue width, and were modeled independently. The relationship between the tissue width and the attenuation coefficient was determined $a$ posteriori by fitting a linear model between the values of both parameters. The root mean square error was estimated as measure of goodness of fit, and $95 \%$ confidence intervals were shown for the estimated parameters.

\subsubsection{Automatic acoustic detection and identification}

Since acoustic features are dependent on distance from the source, we implemented several supervised and unsupervised automatic acoustic detection methods to determine the maximum distance at which species can be reliably identified. We extracted all the stridulations from our recordings using an energy-based segmenter and estimated five acoustic features for each of them (centroid frequency, dominant frequency, bandwidth, duration, and mean amplitude). Then, we used four different clustering algorithms and seven classification techniques to estimate the accuracy of the species identification. 


\subsubsection{Segmentation and feature extraction}

Stridulations were segmented from the spectrogram using a threshold-based approach (Bedoya et al., 2019a). The method consisted of averaging the values of the spectrogram in the time domain, and using the mean value of this new vector as a threshold for identifying the start and end of a stridulation. Five acoustic features were then estimated for each stridulation: the centroid frequency, dominant frequency, bandwidth, duration, and amplitude. The centroid frequency $f_{\mathrm{c}}$ was estimated using: $f_{\mathrm{c}}=\sum_{i=1}^{N_{\mathrm{f}}} f_{i} c_{i} / \sum_{i=1}^{N_{\mathrm{f}}} c_{i}$, where $c_{i}$ is the $\mathrm{i}^{\text {th }}$ value of the mean spectrum, and $f_{i}$ is the current frequency bin. This frequency is analogous to the centre of mass in mechanical systems (Le et al., 2011). The dominant frequency was the frequency bin with the maximum power value. Bandwidths were determined by the upper and lower cut-off frequencies of the mean spectrum of each call (cut-off $3 \mathrm{~dB}$ ). Duration was defined as the length of the call. The mean power of the spectrum was used as the amplitude feature. All the acoustic features were normalized (0-1) before using them as input for the clustering and classification algorithms. Since acoustically detecting the presence of bark beetles is possible even if the specific species cannot be discerned, we also estimated average centroid frequencies throughout the log in order to find the distance at which species are spectrally distinguishable.

\subsubsection{Clustering and Classification}

To evaluate the discernibility of species with distance, all stridulations were clustered into two groups using four unsupervised learning techniques (K-means, Fuzzy c-means (FCM), DBSCAN, and Gaussian mixture models (GMM)) applied on the five extracted acoustic features. For the K-means, the squared Euclidean distance was used as metric for minimization. For the FCM, the fuzzy partition matrix exponent that controls the degree of fuzzy overlap (i.e., the fuzzifier) was set to 2. In the GMM case, model likelihood was optimized using the expectation-maximization algorithm. Finally, for DBSCAN, 50 was selected as the minimum number of points and $\varepsilon=0.25$.

All the classification algorithms (i.e., supervised learning) were trained to identify both species using 5-fold cross-validation (80\% training - 20\% test) at each specific distance. The decision tree used the Gini's diversity index as split criterion with four as maximum number of splits. Linear and quadratic discriminant analyses used full covariance matrices. 
The Naive Bayes Classifier was implemented with a Gaussian kernel, while Support Vector Machines (SVMs) were tested with linear, quadratic, cubic, and gaussian kernels. Results for the K-nearest neighbors algorithm $(\mathrm{KNN})$ are presented for Euclidean, Cosine, and Minkowski distances using equal distance weights and 10 neighbors. Decision trees, linear discriminant analyses (LD), and KNNs were also used in ensemble. Bag ensemble was used for the decision tree (number of learners $=30$, maximum number of splits $=712$ ), whereas both LD and KNN used subspace ensemble (30 learners, and 3 subspace dimensions).

Accuracies, defined as $(\mathrm{Tp}+\mathrm{Tn}) /(\mathrm{T} p+\mathrm{Tn}+\mathrm{Fp}+\mathrm{Fn})$, were reported as general performance measurements for all classification and clustering algorithms. Here, Tp, Tn, Fp, and Fn are the rates of true positives, true negatives, false positives, and false negatives, respectively. Bark beetle acoustic terminology is based on Bedoya et al. (2019a). All figures and mathematical models were coded in Matlab 2018b.

\section{RESULTS}

Hylurgus ligniperda and $H$. ater possess single-note quasiperiodically-repeating calls that are strongly attenuated by the phloem (Fig. 3). With increasing distance, signal intensity decreases and spectral content (e.g., bandwidth) compresses, while some temporal features (e.g., duration) shrink, and others (e.g., inter-syllable interval) expand due to frequencydependent attenuation (Fig. 3). 

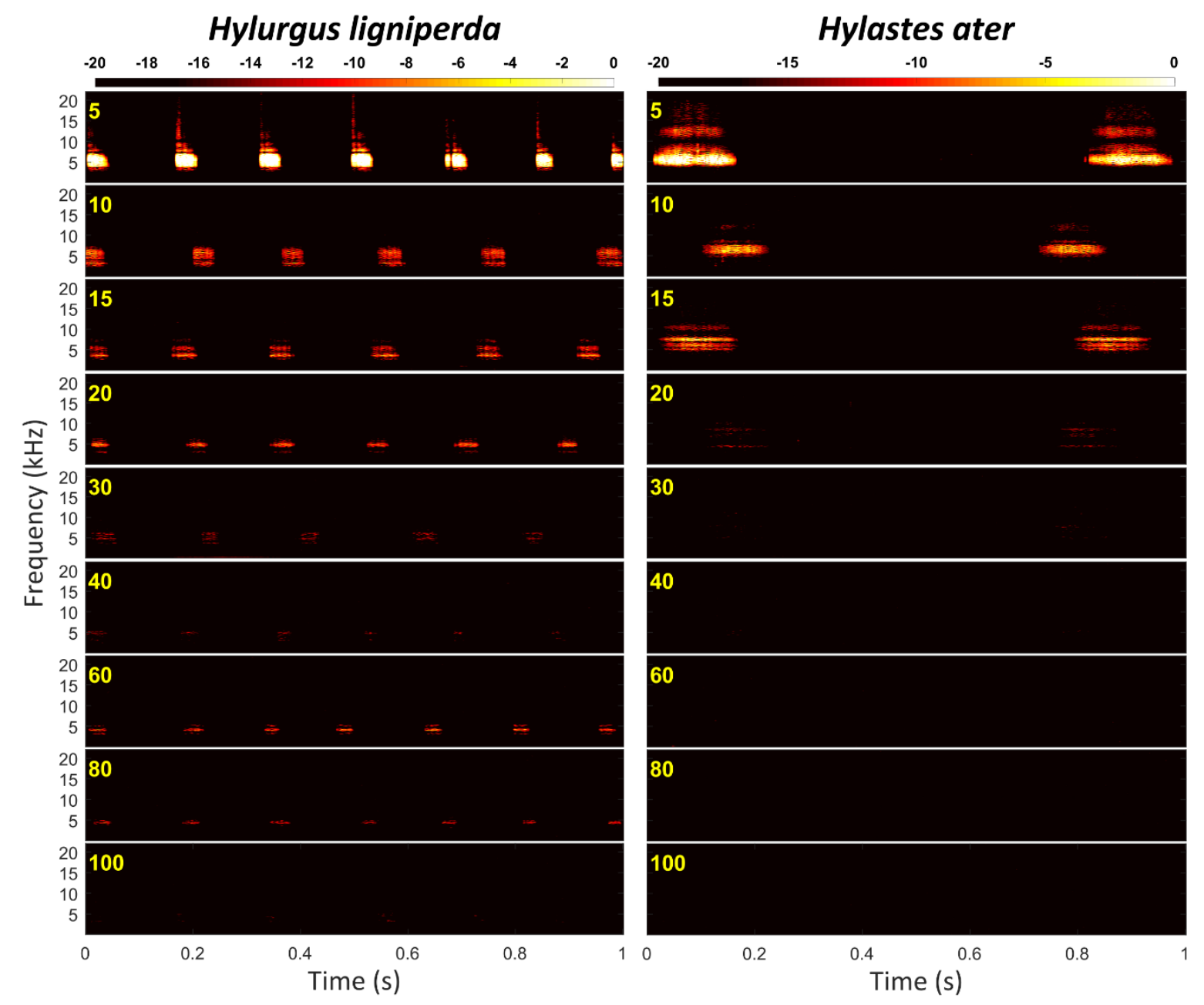

\section{Hylastes ater}

FIG. 3. Stridulations of two individuals of Hylurgus ligniperda (left) and Hylastes ater (right) on Pinus radiata phloem recorded from 5 (top) to 100 (bottom) $\mathrm{cm}$ from source. Colorbars in dBFS. In some individuals, sounds of H. ligniperda are detectable at $100 \mathrm{~cm}$, while those of the smaller $H$. ater are only detectable up to $40 \mathrm{~cm}$.

\subsection{Power decay}

We estimated the power spectra of recordings with $H$. ligniperda and $H$. ater stridulations (Fig. 4). In both species, power was mostly concentrated between 3 and $7 \mathrm{kHz}$, and decayed with distance. Hylurgus ligniperda, the bigger species, had very noticeable power distributions up to $40 \mathrm{~cm}$, whereas $H$. ater had a pronounced decrease in power after $20 \mathrm{~cm}$ (Fig. 4). 
Hylurgus ligniperda

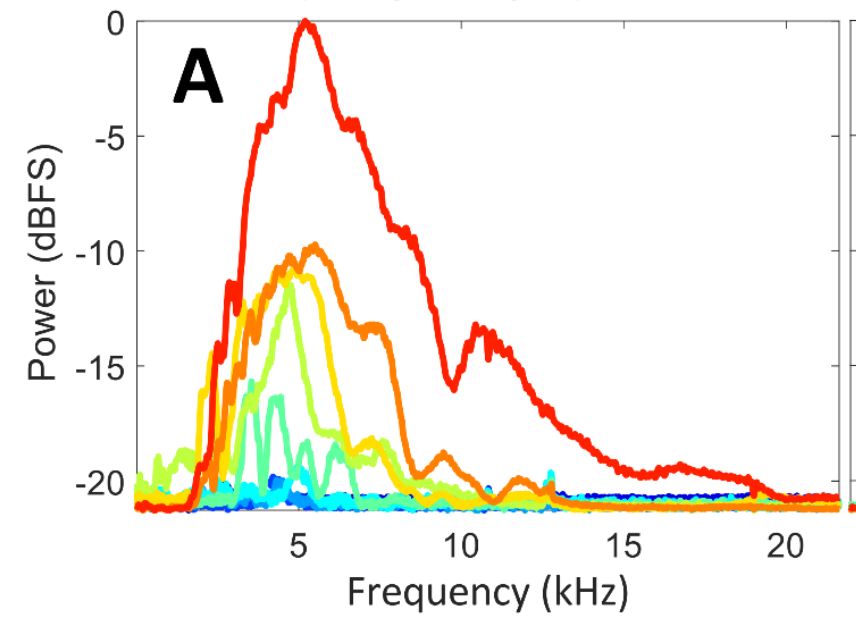

Hylastes ater

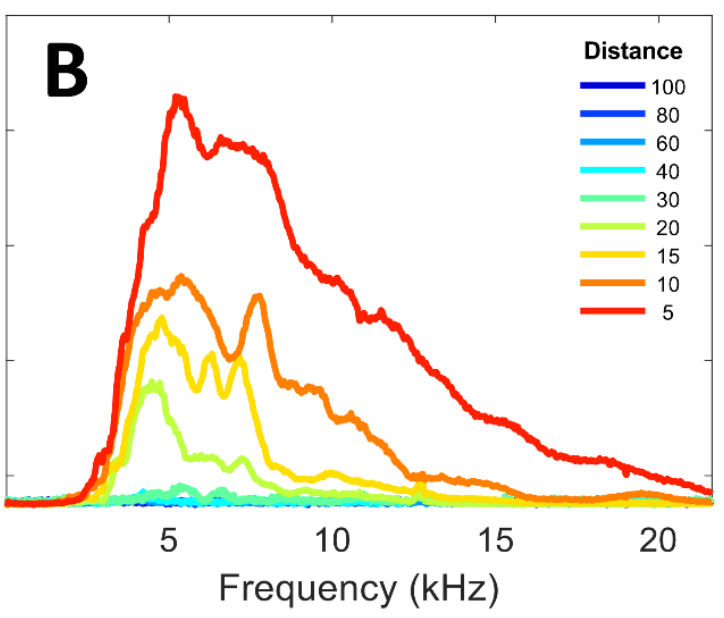

FIG. 4. Average power spectral density (PSD) of the stridulatory sounds of (A) Hylurgus ligniperda and (B) Hylastes ater recorded at distances of 5 to $100 \mathrm{~cm}$ from source. Most power is concentrated between 3 and $7 \mathrm{kHz}$. Averaging was for all individuals of each species, after PSD estimation for the entire dataset (phloem and bark).

In order to localize a specific frequency band for acoustic detection, we divided the spectrum into $2 \mathrm{kHz}$ bands and measured the average power decay at each distance (Fig. 5). The most suitable frequency range for detecting individuals at long distances was 4-6 kHz (Figs. 3, 5). Power decays significantly after $20 \mathrm{~cm}$ for $H$. ater, and $40 \mathrm{~cm}$ for $H$. ligniperda (Fig. 3). After $40 \mathrm{~cm}$, sounds are slightly perceptible for some $H$. ligniperda individuals, but only in the 2-6 kHz frequency band (Figs. 3, 5).

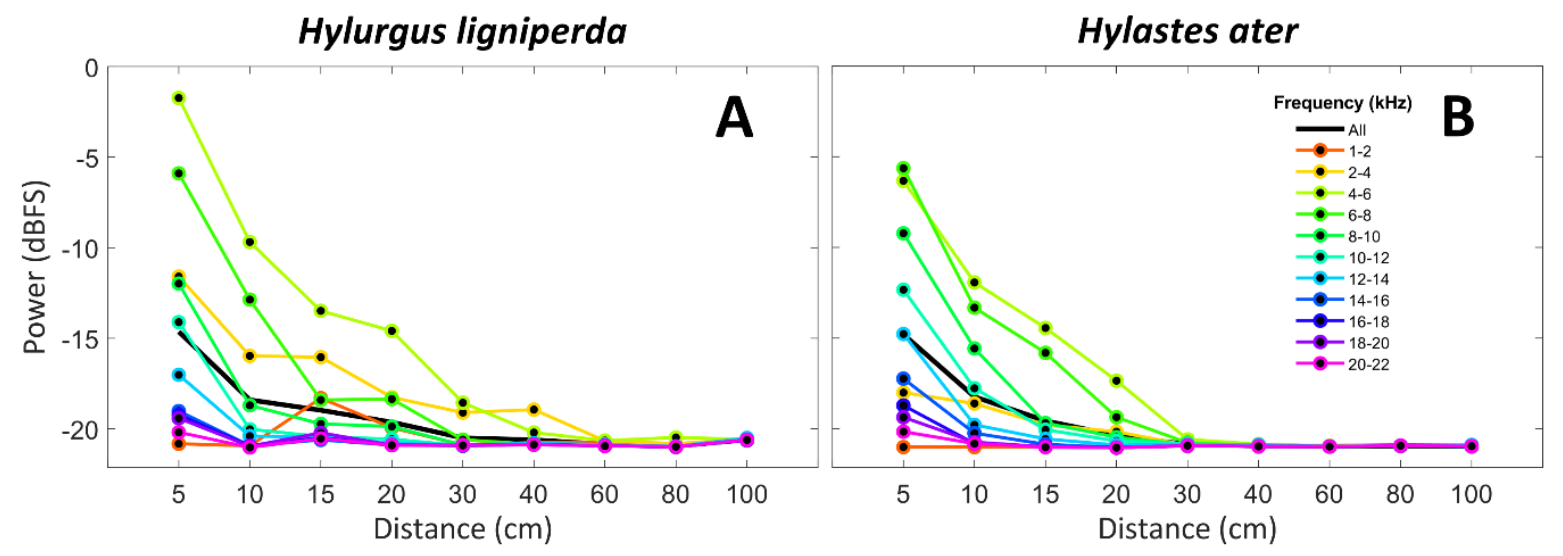


FIG. 5. Average power decay with distance of the stridulations of (A) Hylurgus ligniperda and (B) Hylastes ater estimated in frequency bands of $2 \mathrm{kHz}$ for the entire dataset (phloem and bark). Most stridulations can be detected at their furthest reach using solely the $4-6 \mathrm{kHz}$ frequency band, where spectral components are less attenuated.

\subsection{Attenuation modelling}

Our experimental results show that tissue width significantly reduces power over distance the wider the tissue (bark/phloem), the more the signal amplitude is attenuated (Fig. 7). Attenuation in bark was stronger than in phloem, and Stridulations of $H$. ater (the smaller species) attenuate faster than those of H. ligniperda (Fig. 7, Table I). The phloem is the tissue that transports the soluble organic compounds inside trees; thus, it is more humid and presents less impedance to sound transmission (Yang et al., 2015).
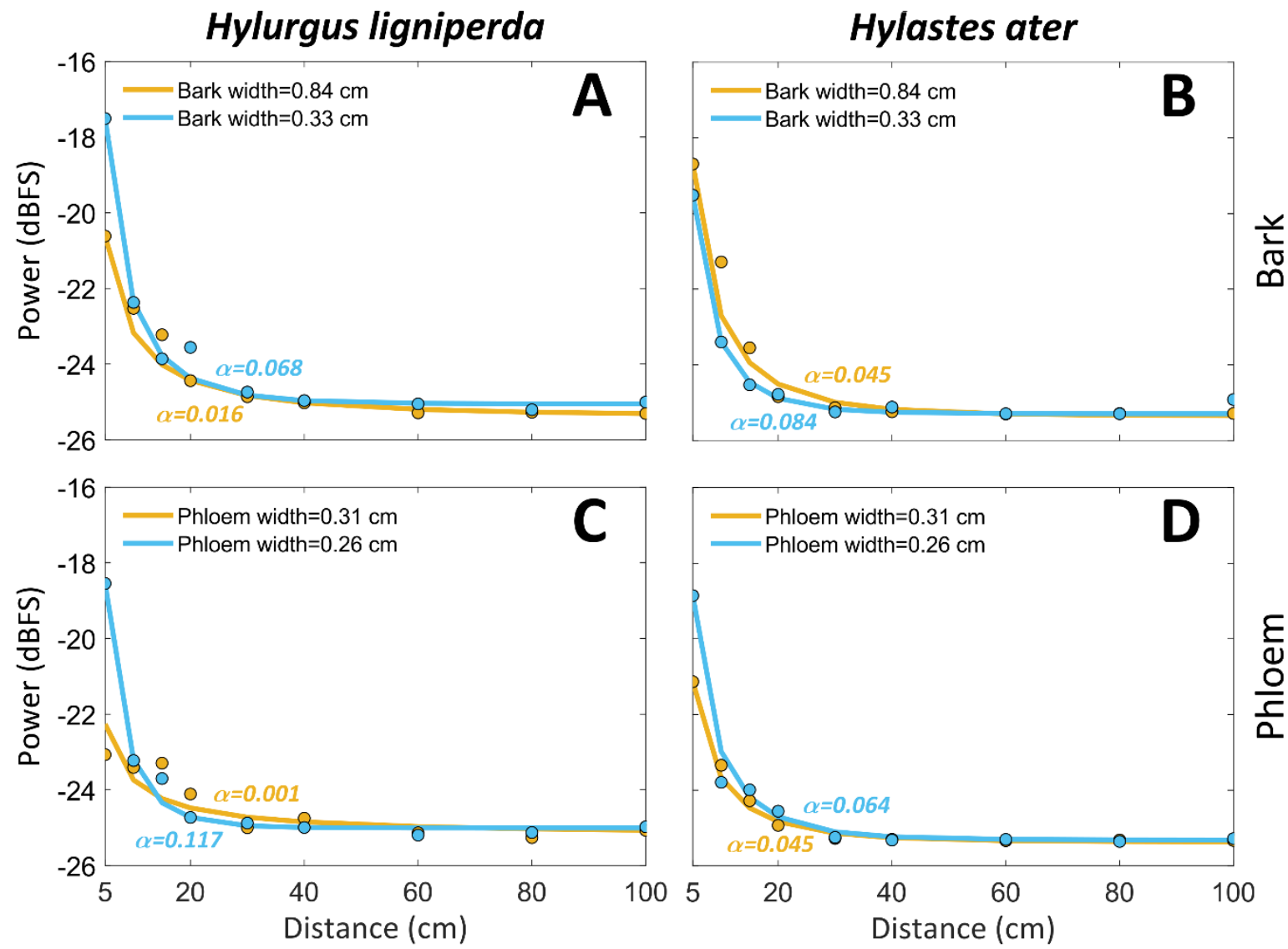

FIG. 7. Experimental models for the power attenuation with distance of stridulatory sounds inside Pinus radiata logs. $\alpha$ is the attenuation coefficient of an exponentially decaying function $\left(\psi e^{(-\alpha \cdot z)} / \varphi z-c\right)$. Models are shown for two different types of tissue (phloem and bark) of different widths, and two bark beetle species (Hylurgus ligniperda and Hylastes ater). Data points represent the average power for all the individuals at that distance. 
TABLE I. Parameters of the experimental models for the power decay with distance of stridulatory sounds inside Pinus radiata bark and phloem. Power levels at each distance were fitted to an exponentially decaying function $P(z)=\psi e^{(-\alpha \cdot z)} / \varphi z-c$, where $z$ is the distance in $\mathrm{cm}$ and $\alpha$ is the attenuation coefficient. The root mean square error (RMSE) is shown as measure of goodness of fit.

\begin{tabular}{|l|l|c|c|c|c|c|c|}
\hline \multicolumn{1}{|c|}{ Species } & Tissue & Width (cm) & $\boldsymbol{\alpha}$ & $\boldsymbol{\Psi}$ & $\boldsymbol{\varphi}$ & $\mathbf{C}$ & RMSE \\
\hline H. ligniperda & Bark & 0.84 & 0.016 & 0.682 & 0.026 & 25.36 & 0.3021 \\
\hline H. ligniperda & Bark & 0.33 & 0.068 & 0.512 & 0.009 & 25.05 & 0.2701 \\
\hline H. ligniperda & Phloem & 0.31 & 0.001 & 0.922 & 0.066 & 25.20 & 0.6128 \\
\hline H. ligniperda & Phloem & 0.26 & 0.117 & 0.796 & 0.014 & 25.01 & 0.3051 \\
\hline H. ater & Bark & 0.84 & 0.045 & 3.359 & 0.080 & 25.34 & 0.6787 \\
\hline H. ater & Bark & 0.33 & 0.084 & 1.062 & 0.024 & 25.28 & 0.1846 \\
\hline H. ater & Phloem & 0.31 & 0.045 & 0.900 & 0.034 & 25.36 & 0.1917 \\
\hline H. ater & Phloem & 0.26 & 0.064 & 1.044 & 0.023 & 25.31 & 0.3857 \\
\hline
\end{tabular}

Aside from the exponential models, we generated linear models to correlate our attenuation coefficients $(\alpha)$ with the width of the tissue:

$$
\begin{aligned}
& \alpha_{\text {bark }}=-0.089 \cdot w_{\text {bark }}+0.106 \\
& \alpha_{\text {phloem }}=-1.364 \cdot w_{\text {phloem }}+0.445
\end{aligned}
$$

where $\alpha_{\text {bark }}$ and $\alpha_{\text {phloem }}$ are the attenuation coefficients $(\mathrm{dB} / \mathrm{cm})$ for bark and phloem, depending on the width of the bark $\left(w_{\text {bark }}\right)$ and the phloem $\left(w_{\text {phloem }}\right)$, respectively, with widths in $\mathrm{cm}$.

\subsection{Species identification}

Our data showed that, for $H$. ater, the centroid frequency stabilizes at $30 \mathrm{~cm}$, and that beyond $40 \mathrm{~cm}$, the two species were indistinguishable using solely spectral content (Fig. 8). 


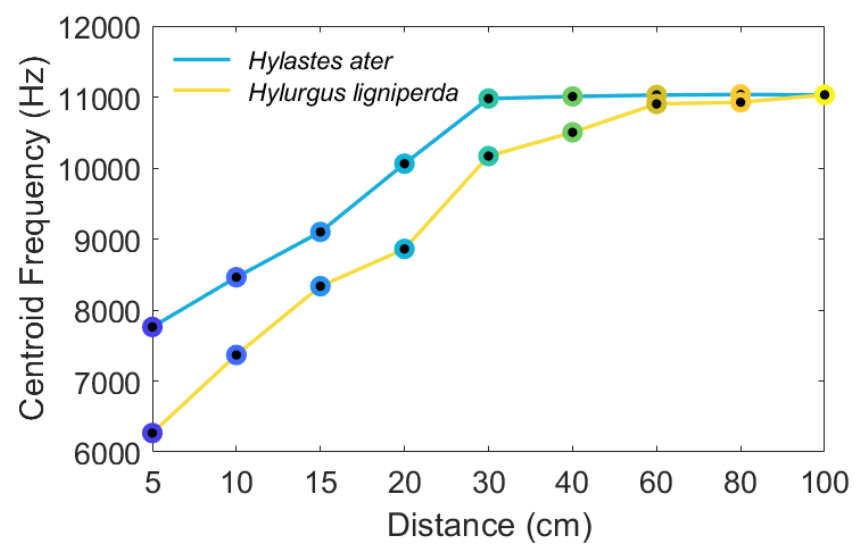

FIG. 8. Centroid frequency of Hylurgus ligniperda and Hylastes ater stridulations. Data points are averages from all 5 individuals. Beyond $40 \mathrm{~cm}$ species-specific stridulations become spectrally indistinguishable.

At distances up to $20 \mathrm{~cm}$, all algorithms were able to accurately and automatically (> $97 \%$ ) discriminate stridulations of $H$. ligniperda from $H$. ater (Table II). After $40 \mathrm{~cm}$, automatic identification reached chance levels, since the stridulations were so attenuated that they could not be discerned (Table II). This phenomenon can be visualized by plotting an ordination of amplitude, frequency, and time features in 2D space, where compact and segregated clusters are observable up to $20 \mathrm{~cm}$ for both species (Fig. 9). After $20 \mathrm{~cm}$, the clusters became sparser until gradually merging at $60 \mathrm{~cm}$, where stridulations of both species are embedded in the same subspace and cannot be discerned (Fig. 9). 
TABLE II. Accuracy results for several supervised and unsupervised machine learning approaches tested for a bi-class clustering/classification task: discriminating Hylurgus ligniperda and Hylastes ater stridulations at different distances.

\begin{tabular}{|c|c|c|c|c|c|c|c|}
\hline \multirow[b]{2}{*}{ Algorithm } & \multicolumn{7}{|c|}{ Accuracy (\%) } \\
\hline & $5 \mathrm{~cm}$ & $10 \mathrm{~cm}$ & $15 \mathrm{~cm}$ & $20 \mathrm{~cm}$ & $30 \mathrm{~cm}$ & $40 \mathrm{~cm}$ & $60 \mathrm{~cm}$ \\
\hline & \multicolumn{7}{|c|}{ Unsupervised Learning } \\
\hline K-means & 100.0 & 100.0 & 99.7 & 99.3 & 90.6 & 74.5 & 51.9 \\
\hline FCM & 99.6 & 100.0 & 100.0 & 99.0 & 81.8 & 71.4 & 50.2 \\
\hline GMM & 99.3 & 100.0 & 100.0 & 99.7 & 89.3 & 80.8 & 51.3 \\
\hline \multirow[t]{2}{*}{ DBSCAN } & 100.0 & 98.0 & 99.7 & 99.7 & 91.8 & 71.6 & 51.6 \\
\hline & \multicolumn{7}{|c|}{ Supervised Learning } \\
\hline Decision Tree & 100.0 & 99.2 & 100.0 & 98.4 & 95.0 & 84.9 & 50.5 \\
\hline Linear Discriminant & 100.0 & 100.0 & 99.7 & 99.7 & 91.2 & 80.5 & 52.3 \\
\hline Quadratic Discriminant & 99.6 & 100.0 & 100.0 & 99.7 & 95.3 & 80.9 & 49.8 \\
\hline Logistic Regression & 100.0 & 100.0 & 100.0 & 99.3 & 91.2 & 81.4 & 52.6 \\
\hline Naive Bayes & 100.0 & 99.6 & 99.7 & 99.0 & 90.9 & 85.8 & 52.3 \\
\hline SVM (Linear) & 100.0 & 100.0 & 99.3 & 99.7 & 92.1 & 81.9 & 51.3 \\
\hline SVM (Quadratic) & 100.0 & 100.0 & 99.3 & 99.3 & 95.6 & 86.2 & 48.2 \\
\hline SVM (Cubic) & 100.0 & 100.0 & 99.3 & 99.7 & 95.3 & 86.9 & 48.5 \\
\hline SVM (Gaussian) & 100.0 & 100.0 & 99.7 & 99.7 & 97.2 & 87.2 & 46.7 \\
\hline KNN (Euclidean) & 100.0 & 100.0 & 99.3 & 99.7 & 95.6 & 85.5 & 52.2 \\
\hline KNN (Cosine) & 100.0 & 100.0 & 99.3 & 97.4 & 97.2 & 86.9 & 49.9 \\
\hline KNN (Minkowski) & 100.0 & 100.0 & 99.3 & 99.0 & 96.5 & 87.1 & 48.0 \\
\hline Bag Ensemble (Decision tree) & 100.0 & 100.0 & 99.7 & 98.4 & 96.9 & 86.9 & 49.6 \\
\hline Subspace Ensemble (LD) & 100.0 & 100.0 & 99.7 & 99.0 & 91.2 & 81.0 & 50.9 \\
\hline Subspace Ensemble (KNN) & 100.0 & 100.0 & 100.0 & 99.3 & 97.2 & 88.1 & 50.1 \\
\hline
\end{tabular}

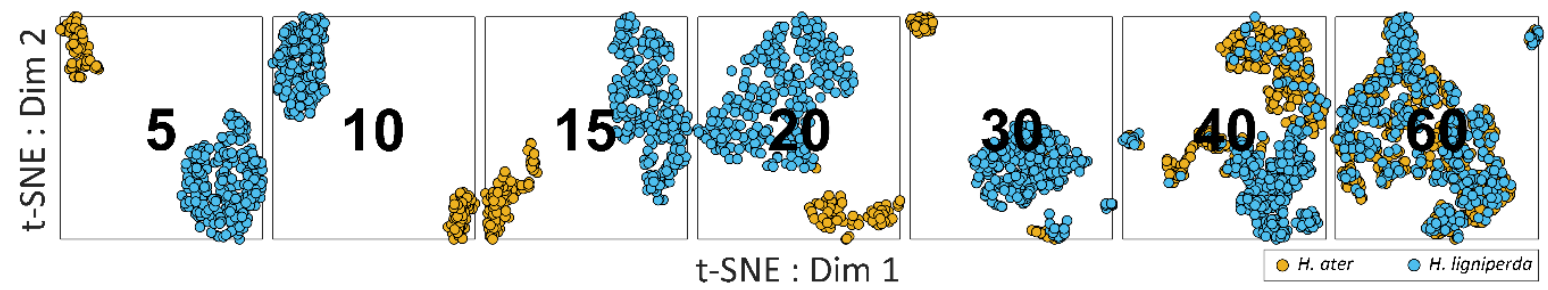

FIG. 9. 2D t-SNE visualization of individual stridulations of Hylurgus ligniperda (blue) and Hylastes ater (yellow) recorded at several distances (cm). Five acoustic features (mean amplitude, dominant frequency, centroid frequency, bandwidth, duration) were used for the ordination. Stridulations of both species become acoustically undistinguishable at $60 \mathrm{~cm}$. 


\section{DISCUSSION}

We characterized the propagation of stridulatory sounds of two bark beetle species $(H$. ater and $H$. ligniperda) through $P$. radiata logs, showing the effects of phloem and bark on signal attenuation over distance. We were able to correctly identify stridulatory sounds from insects of less than six mm length at distances of up to $40 \mathrm{~cm}$. However, spectral content and signal amplitude attenuated with distance, particularly in the phloem tissue. Beyond $20 \mathrm{~cm}$ from the beetle, distance effects reduce the beetle signal bandwidth, which removes the part of the spectrum that allows species identification and makes $H$. ligniperda and $H$. ater stridulations difficult to distinguish. Nevertheless, the remaining content is sufficient to determine the presence of bark beetle activity after $40 \mathrm{~cm}$, and additional temporal features may be used to tell species apart (e.g., call rate and inter-call interval), as these can be reliable speciesspecific descriptors (Bedoya et al., 2019c).

In both species, power was concentrated between 3-7 kHz, which appears to be a general characteristic of Scolytinae (see supplementary material of Bedoya et al., 2019c). We found that 4-6 kHz, where most of the energy is concentrated, was the optimal frequency band to detect stridulations. This frequency is also one of the least attenuated by pine trees (Price et al., 1988). Our results concord with previous experimental models for the propagation of sound inside wood (Burns, 1979; Price et al., 1988), suggesting an acoustic impedance matching between the beetle stridulatory mechanism and the medium. Measurements of sound speed in Pinus radiata have been previously reported for logs and standing trees from New Zealand forests (Wang et al., 2006); consequently, these measurements were not part of our experimental design. The mean sound speed in $P$. radiata is $2277 \pm 496.1 \mathrm{~m} / \mathrm{s}($ mean $\pm \mathrm{SD})$ for standing trees and $2120 \pm 363.5 \mathrm{~m} / \mathrm{s}$ for logs of $3.66 \mathrm{~m}$ long (Wang et al., 2006). Accurate descriptions of the dependence of sound speed in $P$. radiata on tree age, type of tissue, length and width of the tree, and moisture content are described in Grabianowski et al. (2006), Wang et al. (2006), and Toulmin et al. (2007).

We also propose a series of exponential models for the power decay of the stridulations depending on beetle species, type of tissue, and distance. Removing the bark did not significantly reduce the signal power, suggesting that beetles can be accurately detected without removing the bark. Furthermore, our machine learning analyses suggest that species can be reliably identified ( $>97 \%$ accuracy) at short distances of $<20 \mathrm{~cm}$, and with 
relatively good accuracy (> 70\%) up to $40 \mathrm{~cm}$. After $40 \mathrm{~cm}$, our experimental model shows that most of the energy has already dissipated, and none of the tested clustering or classification algorithms was able to provide accurate identification results. Nonetheless, the presence of bark beetles can still be detected at further distances in the 4-6 kHz frequency band if the species is large enough (e.g., H. ligniperda). The accuracies obtained using supervised and unsupervised approaches are almost identical up to $20 \mathrm{~cm}$, from $30 \mathrm{~cm}$ onwards supervised learning techniques become advantageous. However, the increase in accuracy is not large enough to overcome the benefits of unsupervised learning (e.g., no need for data labelling).

As bark beetles are amongst the smallest of the woodborers (Kirkendall et al., 2015), for bigger taxa, such as some pinhole borers (Platypodinae), which tend to generate louder stridulations than most bark beetles (Bedoya et al., 2019c), we would expect similar attenuation patterns and longer detectability ranges than those found here. The smallest woodborer with acoustic communication capabilities (Ips avulsus, $2.5 \mathrm{~mm}$ ) is relatively loud for its size and has a similar amplitude range to $H$. ater (Bedoya et al., 2019c). Consequently, we estimate that deploying an array of sensors spaced at distances of $40 \mathrm{~cm}$ should be enough to detect stridulations of any bark- or wood boring species in logs similar to those of $P$. radiata. The key remaining issue for the detection of the potential presence of such insects is how to elicit ad libitum sound production under the bark of trees, so that the stridulations can be detected in a species-specific manner to identify the presence of woodborers in logs and standing trees. Chemical, acoustic, and luminous stimuli can elicit acoustic communication in several species (Rudinsky and Michael 1972; Hofstetter et al., 2019; Bedoya et al., 2019b). However, integrating these stimuli with acoustic detection and identification methods has yet to be addressed, especially when the target organism is hidden under the bark.

For acoustic identification purposes, deploying an array of sensors $20 \mathrm{~cm}$ apart is enough to detect and identify a species. At distances below $20 \mathrm{~cm}$, between the source and the sensor, the spectral content of the stridulation does not change enough to make the species indistinguishable. Increasing the distance between sensors may increase the detectability range, but may affect the accuracy of the species identification. Depending on the application and the need for accuracy, $40 \mathrm{~cm}$ is a good compromise, as most stridulations are still 
detectable and the identification accuracy is above 70\%. If the acoustic identification set-up is located in an environment with much background noise and the frequency range needs to be restricted, 4 to $6 \mathrm{kHz}$ is a useful band to analyze, as this is where most of the energy is concentrated. Bark beetles live in the phloem, but part of their bodies are usually in contact with the bark tissue, generating a direct coupling with the drier outermost bark layer. Consequently, from the attenuation standpoint, piercing the tree in order to place the sensor in the phloem layer does not appear to provide a substantial benefit, as stridulations attain similar detectability ranges in both types of tissues. Bark is the most accessible contact point between the sensor and the tree stem; thus, placing the sensor on the bark surface of a tree or stem does not jeopardize species detection and does not produce tissue damage.

No studies have been performed on tree soundscapes or acoustic interactions of barkor wood boring beetles in their natural habitat, despite the prevalence of acoustic activity in insects living inside trees. Our study provides a better understanding of the propagation of stridulatory under the bark of trees and contributes towards the development of techniques to study bark- and woodborers in nature. We provide information on how these beetles could be acoustically detected and identified, where to position sensors, and in which part of the frequency of the acoustic spectrum to search for identifying information. We hope this study promotes understanding of acoustic communication inside tree tissues and its role in animal interactions. An appreciation of how stridulatory signals propagate inside tree tissues should aid in our understanding of colonization patterns, gallery structure, and niche-partitioning between cohabitating species. We also hope this work establishes new ground for technological development to aid in automatic acoustic detection approaches for biosecurity purposes. As some bark beetles are of significant economic and biosecurity importance (McCarthy et al., 2013; Grégoire et al., 2015), a clear understanding of acoustic signal propagation through bark and wood can enhance efforts to determine the presence and species identity of potential pest species at borders. 


\section{ACKNOWLEDGEMENTS}

This project was supported by the New Zealand Ministry of Business, Innovation, and

Employment (MBIE), grant C04X1407, the Better Border Biosecurity Collaboration (b3nz.org) via MBIE Core Funding to Scion, and Catalyst: Seeding funding from the Royal Society of New Zealand (grant CSG-FRI1701). 


\section{REFERENCES}

Barr, B. A. (1969). "Sound production in Scolytidae (Coleoptera) with emphasis on the genus Ips," Can. Entomol. 101 (6), 636-672.

Bedoya, C. L., Brockerhoff, E. G., Hayes, M., Pawson, S. M., Najar-Rodriguez, A., and Nelson, X. J. (2019a). "Acoustic communication of the red-haired bark beetle (Hylurgus ligniperda)," Physiol. Entomol. 44 (3-4), 252-265.

Bedoya, C. L., Nelson, X. J., Hayes M., Hofstetter, R. W., Atkinson, T. H., and Brockerhoff, E. G. (2019b). "First report of luminous stimuli eliciting sound production in weevils," Sci. Nat. 106 (17), 1-4.

Bedoya, C. L., Hofstetter, R. W., Nelson, X. J., Hayes, M., Miller, D. R., and Brockerhoff, E. G. (2019c). "Sound production in bark and ambrosia beetles," Bioacoustics.

Birch, M. C., and Keenlyside, J.J. (1991). "Tapping behavior is a rhythmic communication in the death-watch beetle, Xestobium rufovillosum (Coleoptera: Anobiidae)," J. Insect Behav. 4, 257-263.

Brockerhoff, E. G., Knížek, M., and Bain, J. (2003). "Checklist of indigenous and adventive bark and ambrosia beetles (Curculionidae: Scolytinae and Platypodinae) of New Zealand and interceptions of exotic species (1952-2000)," N. Z. Entomol. 26 (1), 29-44.

Burivalova, Z., Game, E. T., and Butler, R. A. (2019). "The sound of a tropical forest," Science. 363 (6422), 28-29.

Burns, S. H. (1979). “The absorption of sound by pine trees," J. Acoust. Soc. Am. 65 (3), $658-661$.

Dumyahn, S. L., and Pijanowski, B. C. (2011). "Soundscape conservation," Landscape Ecol. 26, 1327-1344.

Fleming, A. J., Lindeman, A. A., Carroll, A. L., and Yack, J. E. (2013). "Acoustics of the mountain pine beetle (Dendroctonus ponderosae) (Curculionidae, Scolytinae): sonic, ultrasonic, and vibration characteristics," Can. J. Zool. 91, 235-244.

Grabianowski, M., Manley, B., and Walker, J. C. F. (2006). "Acoustic measurements on standing trees, logs and green lumber" Wood Sci. Technol. 40, 205-216.

Grégoire, J. E., Raffa, K. F., and Lindgren, B. F. (2015). "Economics and politics of bark beetles", in Bark beetles: biology and ecology of native and invasive species, edited by F. Vega and R. W. Hofstetter (Academic Press, CA), pp. 585-613.

Göpfert, M. C., and Hennig, R. M. (2016). "Hearing in insects,” Annu. Rev. Entomol. 61 (1), 257-276.

Haack, R. A., Blank, R. W., Fink, F. T., and Mattson, W. J. (1988). "Ultrasonic acoustical emissions from sapwood of eastern white pine, northern red oak, red maple, and paper birch: Implications for bark- and wood-feeding insects," Fla. Entomol. 71 (4), 427-440.

Hill, P. S. M. (2001). "Vibration and animal communication: A Review," Integr. Comp. Biol. 41 (5), 1135-1142.

Hofstetter, R. W., Aflitto N., Bedoya C. L., Yturralde K., and Dunn D. D. (2019). "Vibrational behavior in bark beetles - applied aspects", in Biotremology - studying vibrational behavior. Animal signals and communication series vol. 6, edited by P.S.M. Hill et al. (Springer), pp. 415-435.

Jalinas, J., B. Güerri-Agulló, B., Dosunmu, O. G., Haseeb, M., Lopez-Llorca L. V., and Mankin R. W. (2019). "Acoustic signal applications in detection and management of Rhynchophorus spp. in fruit-crops and ornamental palms," Fla. Entomol. 102 (3), 475479. 
Kelly, J. F., McGough, R. J., and Meerschaert, M. M. (2008). “Analytical time-domain Green's functions for power-law media,” J. Acoust. Soc. Am. 124 (5), 2861-2872.

Kinsler, L. E., and Frey, A. R. (1962). "Fundamentals of acoustics," New York, Wiley.

Kirkendall, L. R., Biedermann, P. H., and Jordal, B. H. (2015). "Evolution and diversity of bark and ambrosia beetles", in Bark beetles: biology and ecology of native and invasive species, edited by F. Vega and R. W. Hofstetter (Academic Press, CA), pp. 85-156.

Le, P. N., Ambikairajah, E., Epps, J., Sethu, V., and Choi, E. H. C. (2011). "Investigation of spectral centroid features for cognitive load classification," Speech Commun. 53, $540-551$.

Legg, M. and Bradley, S. (2016). "Measurement of stiffness of standing trees and felled logs using acoustics: A review," J. Acoust. Soc. Am. 139 (2), 588-604.

Lai, J. C. S., Oberst, S., and Evans, T. A. (2017). "Termites thrive by using vibrations", in 24th International Congress on Sound and Vibration, ICSV 2017 USA, edited by Gibbs B. (International Institute of Acoustics and Vibration), pp. 1-8.

Lyal C. H. C., and King T. (1996). "Elytro-tergal stridulation in weevils (Insecta: Coleoptera: Curculionoidea)," J. Nat. Hist. 30 (5), 703-773.

Mankin, R. W., Hagstrum, D. W., Smith, M. T., Roda, A. L., and Kairo, M. T. K. (2011). "Perspective and promise: a century of insect acoustic detection and monitoring," Am. Entomol. 57, 30-44.

McCarthy, J. K., Brockerhoff, E. G., and Didham, R. K. (2013). “An experimental test of insect-mediated colonisation of damaged Pinus radiata trees by sapstain fungi," PloS ONE. 8 (2), e55692.

Pijanowski, B. C., Villanueva-Rivera, L. J., Dumyahn, S. L., Farina, A., Krause, B. L., Napoletano, B. M., Gage, S. H., and Pieretti, N. (2011). "Soundscape Ecology: The Science of Sound in the Landscape," BioScience. 61 (3), 203-216.

Price, M. A., Attenborough K., and N. W. Heap, N. W. (1988). "Sound attenuation through trees: Measurements and models," J. Acoust. Soc. Am. 84 (5), 1836-1844.

Raffa, K. F., Grégoire, J. C., and Lindgren, B. S. (2015). "Natural History and Ecology of Bark Beetles", in Bark beetles: biology and ecology of native and invasive species, edited by F. Vega and R. W. Hofstetter (Academic Press, CA), pp. 1-40.

Ross, M., and Masson G. J. (2017). "The effects of preferred natural stimuli on humans' affective states, physiological stress and mental health, and the potential implications for well-being in captive animals," Neurosci. Biobehav. Rev. 83, 46-62.

Rudinsky, J. A., and Michael, R. R. (1972). "Sound production in Scolytidae: chemostimulus of sonic signal by the Douglas-fir beetle," Science. 175, 1386-1390.

Rudinsky, J. A., and Michael, R. R. (1973). "Sound production in Scolytidae: stridulation by female Dendroctonus beetles," J. Insect. Physiol. 19 (3), 689-705.

Ryker, L. C., and Rudinsky, J. A. (1976). "Sound production in Scolytidae - acoustic signals of male and female Dendroctonus valens Leconte," J. Appl. Entomol. 80 (2), 113-118.

Sutin A., Yakubovskiy, S., Salloum, H. R., Flynn, T. J., Sedunov, N., Nadel, H. (2019). "Towards an automated acoustic detection algorithm for wood-boring beetle larvae (Coleoptera: Cerambycidae and Buprestidae)," J. Econ. Entomol. 112 (3), 1327-1336.

Toulmin, M. J., Raymond C. A. (2007). "Developing a sampling strategy for measuring acoustic velocity in standing Pinus radiata using the treetap time of flight tool," N. Z. J. For. Sci. 37, 96-111.

Wang, X., Carter, P., Ross, R. J. (2007) "Acoustic evaluation of wood quality in standing trees. Part 1: acoustic wave behaviour,” Wood Fiber Sci. 39, 28-38. 
Wassilieff, C. (1996). "Sound absorption of wood-based materials." Appl. Acoust. 48 (4), 339-356.

Wood, S. L. (1982). "The bark and ambrosia beetles of North and Central America (Coleoptera: Scolytidae), a taxonomic monograph," Great Basin Nat. Mem. 6, 1-1359.

Yang, H., Yu, L., and Wang, L. (2015). "Effect of moisture content on the ultrasonic acoustic properties of wood." J. For. Res. 26, 753-757.

Yturralde, K. M., and Hofstetter, R. W. (2015). "Characterization of stridulatory structures and sounds of the larger Mexican pine beetle, Dendroctonus approximatus (Coleoptera: Curculionidae: Scolytinae)," Fla. Entomol. 98 (2), 516-527. 